\title{
Comparison of Systemic and Pulmonary Bioavailability of Fluticasone Propionate HFA pMDI 250 Mcg per Actuation With and Without Spacer Device in Healthy Volunteers
}

\author{
Garg $\mathbf{M}^{1 *}$, Naidu $\mathbf{R}^{1}$, Birhade $\mathrm{A}^{1}$, lyer $\mathbf{K}^{1}$, Jadhav $\mathbf{R}^{1}$, Rebello $\mathrm{J}^{2}$, Morde $\mathbf{N}^{2}$ and Brashier $\mathbf{B}^{2}$ \\ ${ }^{1}$ Sitec Labs Pvt. Ltd., PEE-DEE Info Tech, Mahape, Navi Mumbai 400710, India \\ ${ }^{2}$ Cipla Ltd., Peninsula Business Park, Lower Parel, Mumbai 400013, India
}

\begin{abstract}
Fluticasone Propionate (FP) is a topically active corticosteroid which shows little or no systemic activity after oral administration and is indicated for the prophylactic management of asthma of all severities. The aim of these studies was to evaluate systemic exposure and pulmonary deposition of two Hydrofluoroalkane (HFA) formulations of fluticasone propionate with and without a spacer device in, healthy volunteers. Study-1 was a, randomized, single dose, laboratory-blinded, 2-sequence, 4-period, crossover replicate design without volumatic spacer in 32 healthy volunteers under fasting conditions. Study-2 was a randomized, single dose, laboratory-blinded, 2-sequence, 2 -period, crossover design with volumatic spacer in 28 healthy volunteers under fasting conditions. A washout period of 14 days was included in both the studies. Blood samples were collected up to $36 \mathrm{~h}$ post-dose for pharmacokinetic profiling. Safety evaluations included assessment of vital signs, clinical laboratory parameters and monitoring of adverse events. A validated LC-MS/MS method was used to measure the plasma concentrations of fluticasone propionate. The $90 \% \mathrm{Cl}$ of the difference between the test $(\mathrm{T})$ and reference $(\mathrm{R})$ for fluticasone propionate was 97.46-112.34 and 98.55-113.06 for $\mathrm{C}_{\mathrm{max}}$, and $\mathrm{AUC}_{0-\mathrm{t}}$ respectively in study-1. The $90 \% \mathrm{Cl}$ of the difference between the test and reference for fluticasone propionate was 88.13-104.88, and 96.21-111.22 for $C_{\max }$, and $A U C_{0-t}$ respectively in study-2. The $90 \% \mathrm{CI}(T / R)$ for fluticasone propionate for both $\mathrm{C}_{\max }$ and $A \cup \mathrm{C}_{0-\mathrm{t}}$ was within the bioequivalence limits of $80-125 \%$ in both the studies. Hence, it was concluded that test and reference formulations of fluticasone propionate HFA pMDI $250 \mathrm{mcg}$ per actuation are equivalent in the systemic exposure and pulmonary deposition with and without a spacer device.
\end{abstract}

Keywords: Fluticasone propionate; Metered dose inhaler; Inhalational; Volumatic spacer; Bioequivalence; Pharmacokinetics

Abbreviations: $\mathrm{AE}$ : Adverse Event; $\mathrm{AUC}_{0-\mathrm{t}}$ : Area Under the Plasma Concentration Versus Time Curve from Time 0 to Time $t$; $\mathrm{AUC}_{0 \text {-inf }}$ : Area Under the Plasma Concentration Versus Time Curve from Time 0 Extrapolated to Infinity; CFC: Chlorofluorocarbon; $\mathrm{C}_{\max }$ : Maximum Plasma Concentration; CI: Confidence Interval; CV: Coefficient of Variation; ${ }^{\circ} \mathrm{C}$ : Degree Centigrade; $\mathrm{cm}$ : Centimetre; ECGs: Electrocardiograms; g: grams; $\geq$ : Greater Than or Equal to; GCP: Good Clinical Practice; HFA: Hydrofluoroalkane; h(s): hour(s); Ke: Elimination Rate Constant; $\mathrm{kg}(\mathrm{s})$ : Kilogram(s); LC-MS/MS: Liquid Chromatography-Mass Spectroscopy/Mass Spectroscopy; $\leq$ : Less Than or Equal to; LOQ: Lower Limit of Quantification; L/min: Litres/ Minute; Min(s): Minute(s); mm: Millimeter; m: Meter; mL: Milli Liter; mM: Millimol; $\mu \mathrm{l}$ : Microliter; ng/mL: Nano Gram/Milliliter; pMDI: Pressurized Metered Dose Inhaler; \%: Percent; PD: Pharmacodynamics; PK: Pharmacokinetic; rpm: Rotations Per Minute; SAE: Serious Adverse Event; SAS: Statistical Analysis Software; $\mathrm{T}_{\max }$ : Time to Reach; $\mathrm{t}_{1 / 2}$ : Elimination Half-life

\section{Introduction}

Asthma is a chronic disease that manifests itself as episodic dyspnea, wheezing, and cough. Pathophysiologically, asthma is characterized by variable airway obstruction that is associated with an exaggerated response to various broncho-constrictor stimuli [1]. Airway inflammation is associated with airway hyper responsiveness, and several studies have shown that inhaled corticosteroids gradually reduce airway hyper responsiveness, possibly by their anti-inflammatory action [2-5].

Fluticasone Propionate (FP) is an inhaled corticosteroid whose efficacy and safety in the treatment of asthma is well established. It is also highly effective in decreasing airway hyper responsiveness [4,6]. It is widely used for the treatment of chronic asthma worldwide [7-10]. FP is available as pressurized Metered Dose Inhaler (MDI) or a Dry Powder Inhaler (DPI). To overcome coordination between the inhalation efforts with the actuation of the Metered Dose Inhaler (MDI) spacers are utilized. The spacer devices also reduce oro-pharyngeal deposition and possibly increase lung deposition $[11,12]$.

With increasing burden of the respiratory diseases, the demand for easy-to-use and affordable inhaled products is increasing. Often affordable drugs improve management and patient compliance as the obstacle of cost is addressed [13]. The reference Hydrofluoroalkane (HFA) formulation, Flixotide Evohaler (Glaxo Wellcome, France and UK) contains fluticasone propionate. Cipla Limited, India has developed an alternative formulation of fluticasone propionate (test HFA formulation) as a cost-effective alternative for treatment of asthma.

The results of two pharmacokinetic studies are reported that

*Corresponding author: Garg M, MD, Pharmacology, Principal Investigator, Sitec Labs Pvt. Ltd., PEE-DEE Info Tech, Plot No. Gen-40, TTC MIDC, Mahape, Navi Mumbai 400710, India, Tel: +91 9833913773; Fax: +91 222778 6241; Tel: +91 222778 6200/358; E-mail: muneesh.garg@siteclabs.com

Received March 29, 2017; Accepted April 17, 2017; Published April 27, 2017

Citation: Garg M, Naidu R, Birhade A, lyer K, Jadhav R, et al. (2017) Comparison of Systemic and Pulmonary Bioavailability of Fluticasone Propionate HFA pMDI $250 \mathrm{Mcg}$ per Actuation With and Without Spacer Device in Healthy Volunteers. J Bioequiv Availab 9: 399-404. doi: 10.4172/jbb.1000331

Copyright: @ 2017 Garg M, et al. This is an open-access article distributed under the terms of the Creative Commons Attribution License, which permits unrestricted use, distribution, and reproduction in any medium, provided the original author and source are credited. 
Citation: Garg M, Naidu R, Birhade A, Iyer K, Jadhav R, et al. (2017) Comparison of Systemic and Pulmonary Bioavailability of Fluticasone Propionate HFA pMDI $250 \mathrm{Mcg}$ per Actuation With and Without Spacer Device in Healthy Volunteers. J Bioequiv Availab 9: 399-404. doi: 10.4172/ jbb. 1000331

evaluated pulmonary and systemic bioavailability of the two formulations of fluticasone propionate with and without volumatic spacer device under fasting conditions.

\section{Materials and Methods}

\section{Volunteers}

Healthy male subjects aged 18-45 years (body mass index $\geq 18.5 \mathrm{~kg} /$ $\mathrm{m}^{2}$ and $\leq 25.00 \mathrm{~kg} / \mathrm{m}^{2}$ ), in good health participated in both the studies. All subjects had a Forced Expiratory Volume in One Second $\left(\mathrm{FEV}_{1}\right)$ $\geq 80 \%$ of predicted normal. The volunteers were assessed to be healthy based on physical examination, medical history, ECG, pulse oximetry, chest X-ray, and clinical laboratory test results prior to inclusion in the study.

Volunteers were excluded if they took prescription medications or over-the-counter products including herbal products within the 14 days prior to the study drug dosing and also during the study. Exclusion criteria included a history of drugs of abuse, heavy alcohol consumption, active smoking, and inability to use metered dose inhaler satisfactorily.

\section{Informed consent and ethics approval}

The studies were conducted in accordance with the Declaration of Helsinki, current ICH GCP guidelines, European Guidelines on bioequivalence, and the relevant national laws and regulations [14-18].

The study protocols were approved by an independent ethics committee before the start of the study procedures. All volunteers gave written informed consent voluntarily for participating in both the studies after they were explained about the purpose, procedures and anticipated risks of the study. Study 1 (without spacer) was conducted from November, 2011 to January, 2012 and study 2 (with spacer) from July, 2012 to September, 2012.

\section{Study design}

Both studies were similar in design (open-label, randomized, two-treatment, two-sequence, single dose, studies in healthy fasting volunteers), except that the study 1 (without spacer) was a replicate study (4-way crossover) and the study 2 (without spacer) was a two way-crossover study.

The treatment periods were separated by a washout period of at least 14 days in both the studies. The study treatments consisted of the test product fluticasone propionate HFA pMDI $250 \mathrm{mcg} /$ actuation manufactured by Cipla ltd., India, and the reference product Flixotide 250 Evohaler (containing fluticasone propionate $250 \mathrm{mcg}$ per actuation) manufactured by Glaxo Wellcome Production, France.

On check in day, at least $12 \mathrm{~h}$ prior to each dosing, all subjects were screened for drugs of abuse (cocaine, cannabinoids, benzodiazepines, Opioids, Amphetamines, and barbiturates) by urine test and for alcohol consumption by breath alcohol test. Additionally the, volunteers' belongings were thoroughly checked for any restricted items.

\section{Study drug administration}

The investigational products were primed within $10 \mathrm{~min}$ prior to dosing by releasing 2 test sprays into a cardboard box, away from the subjects. This activity was performed within $10 \mathrm{~min}$ prior to individual subject's dosing. After an overnight fast of at least $10 \mathrm{~h}$, subjects selfadministered a single dose of $1000 \mu \mathrm{g}(250 \mu \mathrm{g}$ per actuation $\times 4$ puffs $)$ of test product or reference product as per the randomized sequence in a standing position. In study 2 , the subjects inhaled the dose with the aid of the volumatic spacer.

Dosing was performed under the supervision of a trained and qualified pharmacist, sponsor's monitor and quality assurance personnel. Both the test and reference formulations of fluticasone propionate HFA pMDI $250 \mathrm{mcg} /$ actuation were stored in the pharmacy where the temperature and humidity conditions were monitored continuously till the completion of the study temperature conditions $\left(22 \pm 3^{\circ} \mathrm{C}\right)$ and relative humidity (50 to $\left.60 \%\right)$.

Time of first puff was considered zero for all post-dose activities. Volunteers were vigorously trained on the standardized inhalation technique with the help of training aids and practice placebo inhalers before the dosing during each of the treatment period.

Volunteers were checked-in to the clinical unit at least $12 \mathrm{~h}$ prior to dosing on the previous day during each study treatment period, and they continued to stay at the clinical unit for a minimum of $24 \mathrm{~h}$ after the dosing. They stayed overnight for two consecutive days and two nights, and were provided standard meals at appropriate intervals during their stay. The volunteers refrained from consuming any food and beverages containing xanthine or alcohol $48 \mathrm{~h}$ before dosing and for $24 \mathrm{~h}$ after each dose, grapefruit 7 days before dosing and throughout the study, or vitamins throughout the confinement period.

The volunteers were instructed to be seated for at least the first 2 $\mathrm{h}$ after dosing and were provided standard meals post dose in all the treatment periods of the study. They were not permitted to drink water $1 \mathrm{~h}$ prior to dosing till $2 \mathrm{~h}$ after dosing. Safety evaluations included assessment of vital signs, clinical laboratory parameters and monitoring of adverse events.

\section{Blood sampling}

In both the studies, the pre-dose blood sample $(5 \mathrm{~mL})$ was followed by serial blood sampling ( $5 \mathrm{~mL}$ each) at $0.08,0.25,0.50,0.75,1.00$, $1.50,2.00,2.50,3.00,3.50,4.00,5.00,6.00,8.00,10.00,12.00,18.00$, 24.00 and $36.00 \mathrm{~h}$ post dose. At each time point, blood samples were collected via an indwelling catheter (intra-venous) in vacutainers containing (dipotassium ethylene diamine tetraacetic acid) K EDTA anticoagulant. Plasma was harvested by centrifuging the blood samples at $3000 \mathrm{rpm}$ for $10 \mathrm{~min}$ and was then divided in two portions (main and reserve). Then plasma samples were stored at $-30^{\circ} \mathrm{C}$ or below until sample analysis.

\section{Randomization and blinding}

The volunteers were randomized to either of the treatment groups as per the randomization sequence generated using SAS ${ }^{\circ}$ Version 9.2 software. Since, the study was open-label where investigators had knowledge of the formulation being administered to the volunteer, however, the analyst was blinded.

\section{Analytical methods}

Bio-analysis was performed using liquid chromatography-mass spectrometry (LC-MS)/MS based method. The bio-analytical method for estimation of fluticasone propionate from human plasma was developed and validated as per the international guidelines $[19,20]$.

An aliquot of $500 \mu \mathrm{L}$ of human plasma containing the analyte and the internal standard was extracted using solid phase extraction technique. The internal standard for fluticasone propionate assay was fluticasone D3. About $12.5 \mu \mathrm{L}$ of the internal standard working solution were added to $500 \mu \mathrm{L}$ of plasma sample. After vortexing the tubes, 
Citation: Garg M, Naidu R, Birhade A, Iyer K, Jadhav R, et al. (2017) Comparison of Systemic and Pulmonary Bioavailability of Fluticasone Propionate HFA pMDI $250 \mathrm{Mcg}$ per Actuation With and Without Spacer Device in Healthy Volunteers. J Bioequiv Availab 9: 399-404. doi: 10.4172/ jbb. 1000331

$500 \mu \mathrm{L}$ of $30 \%$ Methanol solution was added and the tubes were again vortexed. This sample was transferred to a pre-conditioned Agilent Bond Elute C18 SPE cartridge. After loading the entire sample, low vacuum was applied to the cartridge till the entire sample has flowed out of the cartridge. Subsequently the cartridge was washed with 1 $\mathrm{mL}$ of $30 \%$ acetonitrile followed by $1 \mathrm{~mL}$ of water. After washing was complete, the analytes were eluted with $0.3 \mathrm{~mL}$ of $100 \%$ Acetonitrile under low vacuum. About $0.2 \mathrm{~mL}$ of this final extract is transferred to glass vial and to it $0.2 \mathrm{~mL}$ of ammonium trifluoroacetate buffer is added and vortexed. This extracted sample is then taken for analysis using LCMS/MS.

The extracts were analysed on the LC-MS/MS system comprising of Schimadzu UFLC XR series HPLC and AB SCIEX Q TRAP 5500/ AB SCIEX TRIPLE QUAD5500 LC-MS/MS System using turbo ion spray source. Positive ions were monitored in the Multiple ReactionMonitoring (MRM) mode. Following ion transitions using analyst 1.5.1 were monitored 501.20/293.20 and 504.20/313.20 for fluticasone propionate and internal standard respectively. Linearity for fluticasone propionate was assessed by plotting area ratios versus standard concentrations and using a linear regression weighted $1 /$ concentration $^{2}$. The calibration standard ranges for fluticasone propionate for both the studies were $3.0-1000 \mathrm{pg} / \mathrm{mL}$ and $3.0-750 \mathrm{pg} / \mathrm{mL}$ respectively. The column used for the analysis is ACE 3 C18 $3 \mu 3.0 \times 100 \mathrm{~mm}$ and the mobile phase composition was a mixture of acetonitrile and trifluro ammonium acetate buffer (65:35). The retention time of fluticasone propionate was $2.34 \mathrm{~min}$ and the acquisition time was $5.0 \mathrm{~min}$.

Method validation was performed according to the current international approach and the applicable regulations regarding bioanalytical method validation. The intra-batch and inter-batch accuracy and precision was evaluated at five different concentrations of control samples. The inter-batch accuracy ranged from 99.77 to $106.67 \%$ and the inter-batch precision ranged from 1.15 to $6.10 \%$. The selectivity of the method was assessed by analysing plasma samples from six sources. Matrix effect was evaluated by performing post-extraction addition and post-column infusion experiments. Stabilities such as stock solution stability, short-term stability of analyte in plasma, freeze-thaw stability, post-preparative stability and long-term stability in plasma were assessed. Fluticasone propionate is stable in plasma for 179 days when stored at $-70 \pm 10^{\circ} \mathrm{C}$.

Incurred sample reanalysis was performed for both studies, and the percentage of samples meeting the acceptance criteria $( \pm 20 \%)$ was 100 and $96.50 \%$ respectively.

\section{Pharmacokinetic analysis}

The primary PK variables were maximum plasma concentration $\left(\mathrm{C}_{\max }\right)$, and area under the plasma concentration curve from administration to last observed concentration at time $\mathrm{t}\left(\mathrm{AUC}_{0-\mathrm{t}}\right)$. The maximum plasma concentration $\left(\mathrm{C}_{\max }\right)$ and the time until $\mathrm{C}_{\max }\left(\mathrm{T}_{\max }\right)$ were taken directly from the plasma concentration time profiles of individual subjects. The area under the plasma concentration time curve $\left(\mathrm{AUC}_{0-\mathrm{t}}\right)$ was calculated by the linear trapezoidal rule from measured data points from the time of administration until the time of the last quantifiable concentration. The other $\mathrm{PK}$ variables were area under the plasma concentration curve extrapolated to infinite time $\left(\mathrm{AUC}_{0-\infty}\right)$, residual area, half-life $\left(\mathrm{t}_{1 / 2}\right)$, and terminal elimination rate constant (Kel). The above PK parameters were calculated using validated PK software (WinNonlin version 5.3 for study-1; and WinNonlin version 6.3 for study-2).
These parameters were derived individually for each subject from the respective plasma concentrations analysed for fluticasone. The actual blood sampling time was used for the PK and statistical calculations. Concentrations below the lower limit of quantification were set to zero for all PK and statistical evaluation. A non-compartmental method was used to calculate the PK parameters using drug concentrations versus time profile.

\section{Safety analysis}

The safety assessment was based on recording Adverse Events (AEs) throughout the study durations. Assessment of vital signs through physical examination, laboratory parameters, and ECGs were performed at the time of screening and at the end of the study. Safety follow up visit was scheduled for individual subjects after 7 days but not later than 15 days of the last treatment period (or earlier if subject dropped out or discontinued early from study or as decided by investigator).

\section{Statistical analysis}

Statistical analysis in both the studies were performed using SAS $^{\circ}$ version 9.2 and above. In both the studies, Analysis of Variance (ANOVA) was performed for the PK endpoints, $\mathrm{C}_{\max }, \mathrm{AUC}_{0-\mathrm{t}}$, and $\mathrm{AUC}_{0-\infty}$. The analysis of variance model included sequence, subjects nested within sequence, period, formulation, and group as factors. Least square means (LSMs) for each parameter, derived from ANOVA, were then calculated for ratio analysis. Ratios of LSMs were calculated for both untransformed and log-transformed parameters; and $90 \%$ $\mathrm{CI}$ for the difference between formulations were calculated for $\mathrm{C}_{\max }$ $\mathrm{AUC}_{0-\mathrm{t}}$, and $\mathrm{AUC}_{0-\infty}$. Wilcoxon signed rank test was used for $\mathrm{T}_{\max }$ comparisons. Concentration values below the LOQ of the assay for fluticasone propionate $(3.0 \mathrm{pg} / \mathrm{mL}$ for study-1 and 2) were set to zero. The $90 \%$ confidence interval of the ratio of $\mathrm{C}_{\max }$, and $\mathrm{AUC}_{0-\mathrm{t}}$ is required to fall between $80.00-125.00 \%$ (transformed values) to conclude bioequivalence. For safety endpoints, descriptive statistics (number and percentage) was used.

The study without spacer was conducted in 28 healthy subjects while the study with spacer was conducted in 32 healthy subjects. The sample size calculation was based on the expected variances in each study. Considering an intra-subject variability of $36.9 \%$ for $\mathrm{C}_{\max }$ of fluticasone propionate (data provided by Cipla Ltd.) for the study without spacer and assuming a test to reference ratio of 0.95 , a minimum of 56 volunteers were required for two period cross-over study design to get $90 \%$ confidence interval (CI) within $80 \%$ to $125 \%$ range, with $90 \%$ power at significance level of $5 \%$ when calculated using $\mathrm{SAS}^{\circ}$ Version 9.2. Therefore, 32 volunteers were recruited for the four period crossover replicate study design to account for any dropout or discontinued subjects if any during the study.

Considering an intra-subject variability of $22.61 \%$ for $\mathrm{AUC}_{0-\mathrm{t}}$ of fluticasone propionate (data provided by Cipla Ltd.) for the study with spacer and a test to reference ratio of 1.0556, a minimum of 23 volunteers were required for two period cross-over study design to get $90 \%$ confidence interval (CI) within $80 \%$ to $125 \%$ range, with $90 \%$ power at significance level of $5 \%$ when calculated using SAS Version 9.2. Therefore, 28 volunteers were recruited for two period crossover study design to account for any dropout or discontinued subjects if any during the study. 
Citation: Garg M, Naidu R, Birhade A, lyer K, Jadhav R, et al. (2017) Comparison of Systemic and Pulmonary Bioavailability of Fluticasone Propionate HFA pMDI $250 \mathrm{Mcg}$ per Actuation With and Without Spacer Device in Healthy Volunteers. J Bioequiv Availab 9: 399-404. doi: 10.4172/ jbb. 1000331

\section{Results}

\section{Study population}

The details of demographic characteristics of the study population included in the individual PK studies are mentioned in Table 1.

In study 1, 32 volunteers were randomised of which 28 volunteers completed the study. 3 volunteers discontinued from the study due to personal reasons and 1 volunteer was discontinued due to unacceptable inhaler technique. In study 2, 28 volunteers were randomised of which 25 volunteers completed the study. There were 3 volunteers who discontinued from study 2 due to personal reasons.

\section{Safety}

In study-1, 4 volunteers (12.50\%) experienced an adverse event. In study-2, 8 volunteers (28.57\%) experienced an adverse event. Summary of the adverse events is presented in Table 2.

All AEs were of mild to moderate severity and resolved completely without any sequalae. No serious adverse events were reported in both the studies. During vital signs examination, ECG and post study clinical laboratory data assessment, there were no clinically significant changes observed from baseline. All volunteers were medically fit in post-study safety assessment.

\section{Pharmacokinetics and statistics}

The mean plasma concentration profiles of fluticasone propionate over 36-h for study 1 and 2 are presented in Figures 1 and 2 respectively. In both the studies, the plasma profile curves between the test and reference product were comparable.

The statistical results of the primary pharmacokinetic parameters of fluticasone propionate for both the studies are presented in Table
3. In both the studies, the $90 \%$ CI for the ratio of the LSMs of test and reference products of ln-transformed data for both the primary parameters $\mathrm{C}_{\max }$ and $\mathrm{AUC}_{0-\mathrm{t}}$ were within the predefined bioequivalence range of $80 \%$ to $125 \%$ (Table 4 ). Hence, the bioequivalence criteria has been met for fluticasone with and without spacer. The mean extrapolated AUC values were found to be less than $20 \%$ for both the formulations in both the studies.

The median $\mathrm{T}_{\text {max }}$ for both test and reference was $1.00 \mathrm{~h}$. in study- 1 while the median $\mathrm{T}_{\max }$ for test was $2.00 \mathrm{hr}$. and for reference was $1.50 \mathrm{~h}$. in study-2. Overall, the $\mathrm{T}_{\max }$ was comparable.

\section{Discussion}

In both the studies, bioequivalence was assessed between the test and reference formulations of fluticasone propionate HFA pMDI 250 mcg/actuation. It is challenging to demonstrate bioequivalence of inhaled drugs due to extremely low levels of drug concentration in the plasma which are not easily detectable. In both the studies conducted, sensitive bio-analytical method with an LLOQ of $3.0 \mathrm{pg} / \mathrm{mL}$ was used to ensure adequate $\mathrm{PK}$ profiling which was done until $36 \mathrm{~h}$ post dose. Standardized inhalation technique training across both the PK studies also minimized variability in the inhalation of the drug across the treatment periods.

The Orally Inhaled Product (OIP) guidelines acknowledge that pharmacokinetic studies are valid for demonstrating equivalent safety and efficacy of two OIPs. Equivalence in terms of efficacy is established via a $\mathrm{PK}$ systemic exposure equivalence study where charcoal is administered to block gastro-intestinal absorption so that only the exposure of the active pharmaceutical ingredient absorbed via the lung is compared. Equivalence in terms of safety is assessed via a PK systemic exposure equivalence study but where charcoal is not administered,

\begin{tabular}{|c|c|c|c|c|c|c|c|c|}
\hline & \multicolumn{4}{|c|}{ Study-1 } & \multicolumn{4}{|c|}{ Study-2 } \\
\hline & Age (years) & Weight (kg) & Height (m) & BMI $\left(\mathrm{Kg} / \mathrm{m}^{2}\right)$ & Age (years) & Weight (kg) & Height (m) & BMI $\left(\mathrm{kg} / \mathrm{m}_{2}\right)$ \\
\hline Number of observations & 32 & 32 & 32 & 32 & 28 & 28 & 28 & 28 \\
\hline Mean & 27.56 & 63.5 & 1.69 & 22.3 & 29 & 60.7 & 1.66 & 22.1 \\
\hline Standard Deviation & 4.86 & 7.3 & 0.05 & 2 & 6 & 6.2 & 0.04 & 1.8 \\
\hline Median & 26.5 & 63 & 1.68 & 22.9 & 27 & 61 & 1.65 & 22.4 \\
\hline Minimum & 21 & 52.9 & 1.58 & 18.7 & 21 & 51.2 & 1.56 & 18.8 \\
\hline Maximum & 39 & 82.8 & 1.83 & 24.8 & 41 & 72.6 & 1.76 & 24.8 \\
\hline
\end{tabular}

Table 1: The demographics of all recruited volunteers in Study-1 (fluticasone propionate HFA pMDI 250 mcg per actuation without a spacer device) and Study-2 (fluticasone propionate HFA pMDI 250 mcg per actuation with a spacer device) are summarized.

\begin{tabular}{|c|c|c|c|c|}
\hline \multirow[t]{2}{*}{ Adverse Event (Preferred Term) } & \multirow[t]{2}{*}{ Frequency (Percentage) } & \multirow[t]{2}{*}{ Relationship } & \multicolumn{2}{|c|}{ Number of Adverse Events } \\
\hline & & & Test product (T) & Reference product (R) \\
\hline \multicolumn{5}{|c|}{ Study-1 } \\
\hline Injection site thrombosis & $3.13 \%$ & Not Related & 0 & 1 \\
\hline Abdominal pain & $3.13 \%$ & Not Related & 1 & 0 \\
\hline Hordeolum & $3.13 \%$ & Not Related & 0 & 1 \\
\hline Eyelid oedema & $3.13 \%$ & Not Related & 1 & 0 \\
\hline \multicolumn{5}{|c|}{ Study-2 } \\
\hline Nasopharyngitis & $7.14 \%$ & Not Related & 1 & 1 \\
\hline Pyrexia & $3.57 \%$ & Not Related & 1 & 0 \\
\hline Dizziness & $3.57 \%$ & Not Related & 0 & 1 \\
\hline Oropharyngeal pain & $3.57 \%$ & Related & 1 & 0 \\
\hline Cough & $3.57 \%$ & Not Related & 0 & 1 \\
\hline Abdominal pain & $3.57 \%$ & Not Related & 1 & 0 \\
\hline Mouth ulceration & $3.57 \%$ & Not Related & 0 & 1 \\
\hline
\end{tabular}

Table 2: Adverse events of Study-1 (fluticasone propionate HFA pMDI 250 mcg per actuation without a spacer device) and Study-2 (fluticasone propionate HFA pMDI 250 mcg per actuation with a spacer device) are summarized. 
Citation: Garg M, Naidu R, Birhade A, lyer K, Jadhav R, et al. (2017) Comparison of Systemic and Pulmonary Bioavailability of Fluticasone Propionate HFA pMDI 250 Mcg per Actuation With and Without Spacer Device in Healthy Volunteers. J Bioequiv Availab 9: 399-404. doi: 10.4172/ jbb.1000331

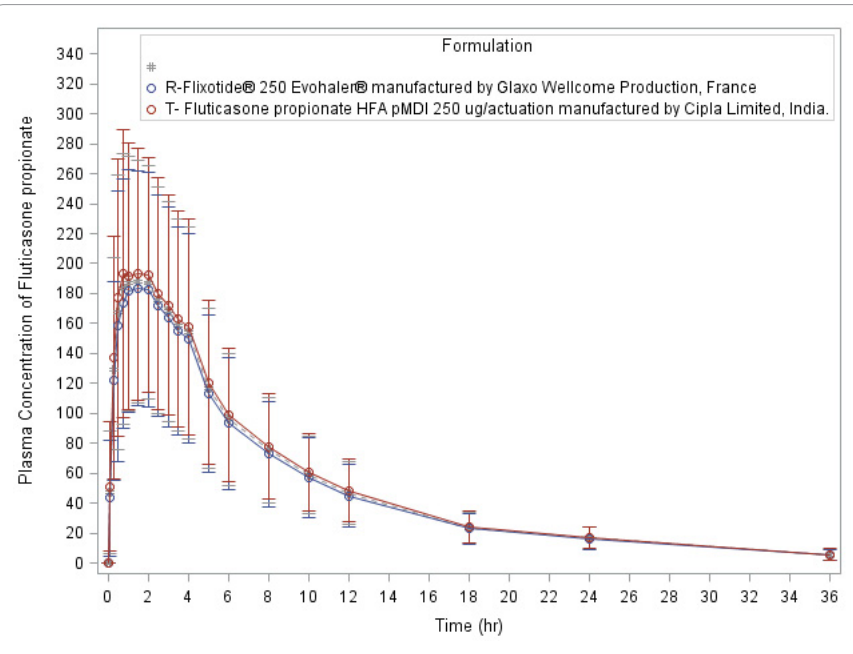

Figure 1: Mean graph (linear) for plasma concentration vs. time profile of Fluticasone propionate after inhalational dose of Fluticasone propionate HFA pMDI 1000 mcg in Study-1 (Fluticasone propionate HFA pMDI 250 mcg per actuation without a spacer device).

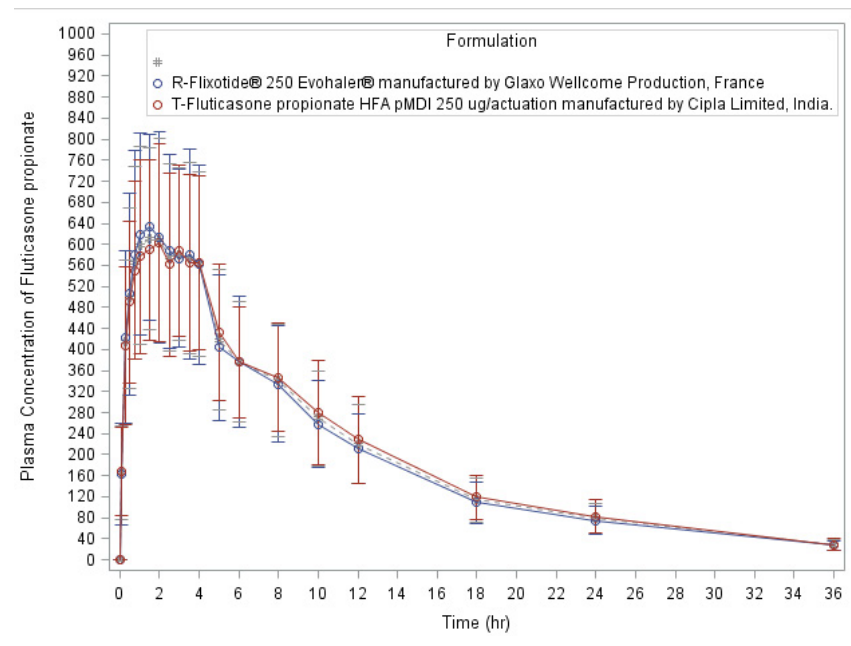

Figure 2: Mean graph (linear) for plasma concentration vs. time profile of Fluticasone propionate after inhalational dose of Fluticasone propionate HFA pMDI 1000 mcg in Study-2 (Fluticasone propionate HFA pMDI 250 mcg per actuation with a spacer device).

\begin{tabular}{|c|c|c|c|c|}
\hline \multirow{2}{*}{$\begin{array}{l}\text { Pharmacokinetic } \\
\text { Parameters }\end{array}$} & \multicolumn{2}{|c|}{ Study-1 } & \multicolumn{2}{|c|}{ Study-2 } \\
\hline & $\begin{array}{c}\text { Test (T) } \\
\text { (Mean } \pm \text { SD) }\end{array}$ & $\begin{array}{c}\text { Reference (R) } \\
\text { (Mean } \pm \text { SD) }\end{array}$ & $\begin{array}{c}\text { Test }(T) \\
\text { (Mean } \pm \text { SD) }\end{array}$ & $\begin{array}{c}\text { Reference (R) } \\
\text { (Mean } \pm \text { SD) }\end{array}$ \\
\hline $\mathrm{N}$ & 56 & 56 & 25 & 25 \\
\hline $\mathrm{C}_{\max }(\mathrm{ng} / \mathrm{mL})$ & $222.97 \pm 96.55$ & $208.34 \pm 86.73$ & $656.50 \pm 180.37$ & $687.25 \pm 199.70$ \\
\hline AUC0-t (h.ng /mL) & $1798.83 \pm 772.15$ & $1683.67 \pm 744.36$ & $7127.75 \pm 2139.82$ & $6898.32 \pm 2111.43$ \\
\hline 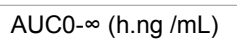 & $1890.35 \pm 798.98$ & $1769.58 \pm 765.67$ & $7529.96 \pm 2299.02$ & $7252.67 \pm 2194.47$ \\
\hline $\mathrm{T}_{\max }(\mathrm{h})$ & $1.00(0.50-3.50)$ & $1.00(0.25-4.00)$ & $2.00(0.50-4.00)$ & $1.50(0.75-10.00)$ \\
\hline Kel $(1 / h)$ & $0.087 \pm 0.018$ & $0.085 \pm 0.018$ & $0.082 \pm 0.009$ & $0.083 \pm 0.013$ \\
\hline $\mathrm{T} 1 / 2(\mathrm{~h})$ & $8.40 \pm 2.06$ & $8.54 \pm 1.73$ & $8.58 \pm 1.07$ & $8.58 \pm 1.35$ \\
\hline
\end{tabular}

${ }^{*}$ Median (range)

Table 3: The statistical results of primary pharmacokinetic parameters for fluticasone propionate of Study-1 (fluticasone propionate HFA pMDI 250 mcg per actuation without a spacer device) and Study-2 (fluticasone propionate HFA pMDI 250 mcg per actuation with a spacer device) are presented.

\begin{tabular}{|c|c|c|c|c|c|c|}
\hline \multirow[t]{2}{*}{ Pharmacokinetic Parameters } & \multicolumn{2}{|c|}{ Geometric Mean } & \multirow[t]{2}{*}{${ }^{*}(\%) T / R$} & \multirow{2}{*}{$\begin{array}{c}90 \% \text { Confidence } \\
\text { Interval }\end{array}$} & \multirow[t]{2}{*}{ Power (\%) } & \multirow{2}{*}{$\begin{array}{c}\text { Intra subject } \\
\text { CV\% }\end{array}$} \\
\hline & Test & Ref & & & & \\
\hline \multicolumn{7}{|c|}{ Study-1 } \\
\hline $\mathrm{N}$ & 56 & 56 & - & - & - & - \\
\hline $\mathrm{C}_{\max }(\mathrm{pg} / \mathrm{mL})$ & 199.41 & 190.57 & 104.64 & $97.46-112.34$ & 99.97 & $22.61^{* *}$ \\
\hline $\mathrm{AUC}_{0-\mathrm{t}}$ (h.pg/mL) & 1610.36 & 1525.58 & 105.56 & $98.55-113.06$ & 99.98 & $22.61^{* *}$ \\
\hline \multicolumn{7}{|c|}{ Study-2 } \\
\hline $\mathrm{N}$ & 25 & 25 & - & - & - & - \\
\hline $\mathrm{C}_{\max }(\mathrm{pg} / \mathrm{mL})$ & 631.5617 & 656.8985 & 96.14 & $88.13-104.88$ & 99.33 & 18.08 \\
\hline$A \cup C_{0-t}(h . p g / m L)$ & 6832.3683 & 6604.943 & 103.44 & $96.21-111.22$ & 99.92 & 15.02 \\
\hline
\end{tabular}

*(\%) T/R is ratio of Test Geometric Mean/Ref Geometric Mean

**intra-subject variability for reference product

Table 4: The Geometric mean ratios, $90 \%$ Cls, power and intra subject coefficient of variation of test and reference for Ln transformed pharmacokinetic parameters $\mathrm{C}$ and $\mathrm{AUC}_{0-\mathrm{t}}$ for fluticasone propionate of Study-1 (fluticasone propionate HFA pMDI 250 mcg per actuation without a spacer device) and Study-2 (fluticasone propionate HFA pMDI 250 mcg per actuation with a spacer device) are presented.

so that the total systemic exposure of the generic versus the reference product are compared, not just what is absorbed via the lung [18,21].

Drug concentrations in the blood represent fractions of the aerosolized dose that has reached the blood after absorption from the gastrointestinal tract and the peripheral absorption from the lungs, which determines the safety of the administered drug. The extent to which the swallowed portion is absorbed depends on the oral bioavailability of the drug. Fluticasone propionate has negligible oral bioavailability $(<1 \%)$ due to a combination of incomplete absorption from the gastro-intestinal tract and extensive first-pass metabolism, therefore systemic exposure arises only from pulmonary absorption i.e., lungs [22-24]. The amount of drug that reaches the blood via absorption from the lungs is same as the total bioavailability of the drug. Therefore, PK study using oral charcoal blockade to block the gastrointestinal absorption of inhaled fluticasone propionate for comparison of the pulmonary bioavailability of the test product and the reference product is not required.

Hence, both the PK studies conducted were useful to compare the 
Citation: Garg M, Naidu R, Birhade A, lyer K, Jadhav R, et al. (2017) Comparison of Systemic and Pulmonary Bioavailability of Fluticasone Propionate HFA pMDI 250 Mcg per Actuation With and Without Spacer Device in Healthy Volunteers. J Bioequiv Availab 9: 399-404. doi: 10.4172/ jbb. 1000331

pulmonary and systemic bioavailability of the test product and the reference product with and without spacing device.

Both the studies confirm that both formulation of fluticasone propionate showed a similar rate and extent of bioavailability of fluticasone propionate. Since the test product has been shown to have equivalent pulmonary absorption and systemic exposure as that of the reference product, it is expected to have equivalent efficacy and safety as well.

Both the products were well tolerated after self-administration of a single dose of fluticasone propionate HFA pMDI $1000 \mu \mathrm{g}(250 \mu \mathrm{g}$ per actuation $\times 4$ puffs) by the subjects with and without a spacer device. All AEs were of mild to moderate severity and resolved completely without any sequalae. No serious adverse events were reported in both the studies.

\section{Conclusion}

Overall it is concluded that the test product fluticasone propionate HFA pMDI (CIPLA LTD., INDIA) is therapeutically equivalent to the reference formulation of Flixotide Evohaler manufactured by Glaxo Wellcome Production, France.

\section{Acknowledgement}

These bioequivalence studies were conducted at Sitec Labs. Pvt. Ltd., Mumbai, India. Dr. Muneesh Garg was the Principal Investigator for the studies, wrote the manuscript, and reviewed and approved the final draft. Dr Raghu Naidu was responsible for the bio-analysis. This publication was supported by Sitec Labs., India; and Cipla Ltd., India was the sponsor of these studies.

\section{Conflict of Interest}

The authors have indicated that they have no other conflicts of interest regarding the content of the article. The authors are thankful to the volunteers who participated in these studies.

\section{References}

1. Hargreave FE, Dolovich J, O'Byrne PM, Ramsdale EH, Daniel EE (1986) The origin of airway hyperresponsiveness. J Allergy Clin Immunol 78: 825-832.

2. Boushey HA, Holtzman MJ (1985) Experimental airway inflammation and hyperreactivity. Searching for cells and mediators. Am Rev Respir Dis 131: 312-313.

3. Noonan MJ, Chervinsky P, Wolfe J, Liddle R, Kellerman DJ, et al. (1998) Dose-related response to inhaled fluticasone propionate in patients with methacholine-induced bronchial hyperresponsiveness: a double-blind, placebo-controlled study. J Asthma 35: 153-164.

4. Bootsma GP, Dekhuijzen PNR, Festen J, Mulder PG, van Herwaarden CL (1995) Comparison of fluticasone propionate and beclomethasone propionate on direct and indirect measurements of bronchial hyperresponsiveness in patients with stable asthma. Thorax 50: 1044-1050.

5. Djukanovic R, Wilson JW, Britten KM, Wilson SJ, Walls AF, et al. (1992) Effect of an inhaled corticosteroid on airway inflammation and symptoms in asthma. Am Rev Respir Dis 145: 669-674.

6. Westbroek J, Pasma HR (2000) Effects of 2 weeks of treatment with fluticasone propionate $100 \mu \mathrm{g}$ b.d. by comparison with zafirlukast $20 \mathrm{mg}$ b.d. on bronchial hyper-responsiveness in patients with mild to moderate asthma. Respir Med 94: 112-118.

7. Adams NP, Bestall JC, Lasserson TJ, Jones PW (2005) Inhaled fluticasone versus placebo for chronic asthma in adults and children. Cochrane Database of Syst Rev 2: CD003135.

8. Barnes PJ, Pedersen S, Busse WW (1998) Efficacy and safety of inhaled corticosteroids. New developments. Am J Respir Crit Care Med 157: S1-53.
9. Pedersen D, O'Byrne P (1997) A comparison of the efficacy and safety of inhaled corticosteroids in asthma. Allergy: European Journal of Allergy \& Clincal Immunology 52: S1-S34.

10. https://www.medicines.org.uk/emc/medicine/2913

11. Lundback R, Dahl R, DeJonghe M, Hyderbrendt N, Valta R, et al. (1994) A comparison of fluticasone propionate when delivered by either the metereddose inhaler or the Diskhaler inhaler in the treatment of mild-to-moderate asthma. Eur J Clin Res 5: 11-19.

12. Cripps A, Riebe M, Schulze M, Woodhouse R (2000) Pharmaceutical transition to non-CFC pressurized metered dose inhalers. Respir Med 94: S3-S9.

13. Bera A, Mukherjee A (2012) The importance of generic drugs in India. IJPCBS 2: $575-587$.

14. World Medical Association Declaration of Helsinki (2008) Ethical principles for the medical research involving human volunteers adopted by the: $59^{\text {th }}$ General Assembly Seoul, Korea.

15. International Conference on Harmonisation of technical requirements for registration of pharmaceuticals for human use (2001) ICH harmonized tripartite guideline: Guideline for Good Clinical Practice. J Postgrad Med 47: 45-50.

16. ICMR Guidelines (2006) Ethical Guidelines for Biomedical Research on Human Participants. Indian Council of Medical Research, New Delhi, India, pp: 1-111.

17. Schedule $Y$ (2014) Requirements and guidelines for permission to import and/ or manufacture of new drugs for sale or to undertake clinical trials. Central Drugs Standard Control Organization, New Delhi, India.

18. Committee for medicinal products for human use (CHMP) (2009) Guideline on the requirements for clinical documentation for orally inhaled products (OIP) including the requirements for demonstration of therapeutic equivalence between two inhaled products for use in the treatment of asthma and chronic obstructive pulmonary disease (COPD) in adults and for use in the treatment of asthma in children and adolescents. European medicines agency, London.

19. Guideline on Bioanalytical Method Validation (2011) Committee for medicinal products for human use (CHMP). European medicines agency, London.

20. Food and Drug Administration (FDA) (2013) Guidance for industry bioanalytical method validation. USA.

21. Lu D, Lee SL, Lionberger RA, Choi S, Adams W, et al. (2015) International guidelines for bioequivalence of locally acting orally inhaled drug products: Similarities and differences. AAPS J 17: 546-557.

22. Kunka R, Andrews S, Pimazzoni M, Callejas S, Ziviani L, et al. (2000) Dose proportionality of fluticasone propionate from hydrofluroalkane pressurised metered dose inhalers (pMDIs) and comparability with chloroflurocarbon pMDI. Respir Med 94: S10-S16.

23. Blake K, Mehta R, Spencer T, Kunka RL, Hendeles L (2012) Bioavailability of inhaled fluticasone propionate via chambers/masks in young children. Eur Respir J 39: 97-103.

24. Dempsey OJ, Coutie WJ, Wilson AM, Williams P, Lipworth BJ (1999) Evaluation of the buccal component of systemic absorption with inhaled fluticasone propionate. Thorax 54: 614-617. 